\title{
Erratum to: Youth personal identity as a factor in the formation of a time perspective
}

Irina Ralnikova ${ }^{1, *}$, Yana Smirnova ${ }^{1}$

${ }^{1}$ Altai State University, 656049, 61 Lenin ave., Barnaul, Russia

Original article: SHS Web of Conferences 55, 02029 (2018), https://doi.org/10.1051/shsconf/20185502029

The second author, Yana Smirnova, should be replaced with Marina Shamardina:

Irina Ralnikova ${ }^{1, *}$, Marina Shamardina ${ }^{1}$

${ }^{1}$ Altai State University, 656049, 61 Lenin ave., Barnaul, Russia

Information about grant support should be included into the paper (after conclusion):

The research was carried out with the support of the Russian Foundation for Basic Research, project No. 17-36-00023ОГН "Vital perspectives of a man in a changing world." 